\title{
Microfluidic Technology for Cell Manipulation
}

\author{
Jae-Sung Kwon ${ }^{1, *}$ and Je Hoon $\mathrm{Oh}^{2, *}$ \\ 1 Department of Mechanical Engineering, Incheon National University, 119 Academy-ro, Yeonsu-gu, \\ Incheon 22012, Korea \\ 2 Department of Mechanical Engineering, Hanyang University, 55 Hanyangdaehak-ro, Sangrok-gu, Ansan, \\ Gyeonggi-do 15588, Korea \\ * Correspondence: jsungkwon@inu.ac.kr (J.-S.K.); jehoon@hanyang.ac.kr (J.H.O.); \\ Tel.: +82-032-835-8097 (J.-S.K.); +82-031-400-5252 (J.H.O.)
}

Received: 26 April 2018; Accepted: 14 June 2018; Published: 17 June 2018

Featured Application: Microfluidic manipulation techniques not only improve the efficiency and reliability of biological/clinical analysis, but also further enable the development of a high-performance bioassay system.

\begin{abstract}
Microfluidic techniques for cell manipulation have been constantly developed and integrated into small chips for high-performance bioassays. However, the drawbacks of each of the techniques often hindered their further advancement and their wide use in biotechnology. To overcome this difficulty, an examination and understanding of various aspects of the developed manipulation techniques are required. In this review, we provide the details of primary microfluidic techniques that have received much attention for bioassays. First, we introduce the manipulation techniques using a sole driving source, i.e., dielectrophoresis, electrophoresis, optical tweezers, magnetophoresis, and acoustophoresis. Next, we present rapid electrokinetic patterning, a hybrid opto-electric manipulation technique developed recently. It is introduced in detail along with the underlying physical principle, operating environment, and current challenges. This paper will offer readers the opportunity to improve existing manipulation techniques, suggest new manipulation techniques, and find new applications in biotechnology.
\end{abstract}

Keywords: cell manipulation; dielectrophoresis; electrophoresis; optical tweezers; magnetophoresis; acoustophoresis; rapid electrokinetic patterning

\section{Introduction}

Microfluidics is the science and technology of manipulating and processing colloidal systems including fluids and particles at the micro- or nano-scale [1]. With the rapid development of microfabrication technology during the past two decades, microfluidics technology has been integrated in small chips for realization of the lab-on-a-chip (LOC) system, where all laboratory tasks for material treatment and analysis can be performed in an automated manner. The integrative system has numerous advantages originating from scale-down compared to conventional macro-sized devices. Specifically, they offer low cost, short reaction time, small reagent and power consumption, less waste output, and high integration efficiency of microfluidic components for multi-parallel processing [1-3]. Those advantages have triggered wide applications in various research and industry fields, including life science [4-6], inkjet printing [7-10], micro-air vehicles [11-13], automobiles [14,15], robotics [16,17], and microelectronics [18-20]. Among these fields, the largest beneficiary of microfluidics is biotechnology, which often requires precise manipulation and fast pretreatment of cell suspensions and accurate detection of target cells for biological assays. The ability to move motile or non-motile cells in a controlled fashion improved the efficiency and reliability of biological/clinical analysis and further 
enabled the development of high-performance miniaturized total analysis systems ( $\mu$ TAS) $[3,5,21]$. Particularly, the trapping, isolation, and analysis of a single cell allowed resolution of many unsolved questions in biology by providing information about the physical and biological behaviors of individual cells in a cell population [2]. This led to the creation of new research fields such as single-cell genomics, transcriptomics, proteomics, and metabolomics, improving many existing clinical and biomedical applications [22,23].

A main focus is on how precisely and fast cell manipulation can be performed in a non-invasive manner [3,24-26]. To date, various microfluidic manipulation techniques to meet the requirements have been developed and integrated into a chip for high-resolution, high-throughput, and non-contaminating biological assays. The primary techniques are dielectrophoresis and electrophoresis utilizing interactions of polarity or gradients of applied electric fields and net charges of manipulated particles [27-30], optical tweezers using the scattering force and the gradient force delivered from a focused laser beam [31-34], magnetophoresis driven by application of magnetic field gradients to particles with magnetic susceptibility [35-38], and acoustophoresis wherein particle motion is controlled using acoustic waves with varying pressure profiles [39-41]. Additionally, there also have been other microfluidic approaches using inertial focusing and hydrodynamic stretching [42], optical stretching [43], and pressure gradients [44,45]. These techniques have been consistently applied for concentration, separation, sorting, isolation, and transport of cells [46-49]. However, applications also revealed the drawbacks of each manipulation technique. For example, dielectrophoresis requires a complex 3D electrode structure for precise cell manipulation [5]. In addition, it is difficult to control nano-sized cells because the dielectrophoretic force is proportional to the volume of a manipulated object [50,51]. Electrophoresis, another electric field-based technique, is applicable only for charged particles [28]. Accordingly, its application range for cell manipulation is not very wide $[52,53]$. In addition, the electrophoretic migration speed of cells is low [24]. The use of optical tweezers is typically limited to manipulation of a single or a few cells because of the narrow beam waist of a focused laser $[6,27,33,54]$. The high heat in the laser beam may cause cell damage and lysis [34]. Magnetophoresis involves magnetic hysteresis-induced cell aggregation or clustering [55]. Also, this technique requires magnetic bead labeling for cell manipulation. Finally, it is difficult to manipulate nanoscale cells using acoustophoresis [24]. Due to those disadvantages, the techniques have been used only for specific purposes in biological assays [3,5,21,23,39].

There have been recent attempts to develop a new type of microfluidic manipulation technique. One approach is to combine two individual manipulation methods so that their advantages and disadvantages can be synergized and complemented, respectively $[4,5,26,33,56-59]$. Based on this combination, particles are manipulated by separate mechanisms for each of the two driving sources and a new mechanism derived from the interaction of the two driving forces. Rapid electrokinetic patterning (REP) is an example of the hybrid manipulation technique [26,58,60-63]. REP is a non-invasive manipulation technique that utilizes the simultaneous application of a uniform alternating current (AC) electric field and an optical laser beam. The technique can manipulate a large quantity of micro- and nano-sized particles at once at an arbitrary location in a microfluidic chip through electrokinetic and optical effects of each of the two driving sources and the electrothermal effect caused by the interaction of the two $[26,58,64]$. This capability has been demonstrated in various experiments. Williams et al. carried out particle manipulation in a variety of forms using REP [61-63]. Micro-sized colloids were rapidly trapped and configured into various shapes on an electrode surface by the optical landscapes produced by an $\mathrm{Nd}_{\mathrm{YVO}} \mathrm{VO}_{4}$ laser under the application of a uniform electric field. The particles were aggregated, and their clusters were translated across the electrode surface by dynamically controlling the location of the focused laser. Kwon et al. first demonstrated the bio-compatibility of REP with several kinds of microorganisms [24,25,64]. A large quantity of motile Shewanella oneidensis MR-1 bacteria was trapped, concentrated, and transported using the technique. Also, size-based separation and sorting of Saccharomyces cerevisiae fungus and Staphylococcus aureus bacteria were achieved. However, the applications of REP for biological assay are still at an early 
stage despite confirmation of their bio-compatibility because of the limited economics, portability, and versatility of the microfluidic manipulation system where the technique is used [24,26].

As seen above, microfluidic techniques for cell manipulation have been evolving. However, the limitations of each of the techniques often hinder further advancement and applications. To overcome this difficulty, examination of the various aspects of the manipulation techniques is necessary. In this review, we provide the details of the primary microfluidic techniques that have received much attention for on-chip biological assays. We first introduce manipulation techniques using a sole driving source: (1) dielectrophoresis, (2) electrophoresis, (3) optical tweezers, (4) magnetophoresis, and (5) acoustophoresis. The techniques are described based on fundamental principles, advantages and disadvantages, and a brief introduction of their existing applications. Next, we present REP, the recently developed hybrid manipulation technique that has been introduced briefly [24]. However, as there have since been new advancements in the technique, we provide an update related to REP, in addition to describing the underlying physical principle, operating environment, and current challenges. This review will offer readers the opportunity to improve the existing manipulation techniques and help them find new applications for the techniques in biotechnology.

\section{Microfluidic Manipulation Techniques}

\subsection{Dielectrophoresis}

Among the various mechanisms to manipulate particles using electrically induced forces, dielectrophoresis (DEP) is the most frequently utilized in microfluidic systems [29,40,48,51,65-70]. DEP is defined as the motion of neutral or semi-conducting particles produced by the application of a non-uniform electric field $[40,51,71,72]$. Under the presence of an electric field, a particle experiences polarization resulting in a net dipole moment within the particle. If the electric field is not uniform, the Coulomb forces acting on the two poles become unequal. Then, the net resulting force causes the particle to move (Figure 1). The particle migration phenomenon is termed DEP, and the related DEP force is generally expressed in a time-averaged manner using the following equation [40,51]:

$$
F_{D E P}=\frac{1}{2} \operatorname{Re}[\widetilde{p} \cdot \nabla] E^{*},
$$

where $\widetilde{p}$ is the effective dipole moment of a particle, $E^{*}$ is the complex conjugate of an applied electric field, and $\operatorname{Re}$ and $\nabla$ represent the real part in brackets and the differential operator, respectively. For a spherical particle with radius $r$, the equation is re-written as [51]

$$
F_{D E P}=2 \pi r^{3} \varepsilon_{m} \operatorname{Re}[K(\omega)] \nabla\left|E_{r m s}\right|^{2},
$$

where $\varepsilon_{m}$ is the absolute electrical permittivity of suspending medium, $K(\omega)$ is the Clausius-Mossotti $(\mathrm{CM})$ factor, $\omega$ is the angular frequency of an applied electric field, and $E_{r m s}$ is the root mean square ( $r m s$ ) of electric field strength. The CM factor is expressed as the difference of complex permittivity of a particle $\left(\varepsilon_{p}^{*}\right)$ and surrounding medium $\left(\varepsilon_{m}^{*}\right)$ as follows [51]:

$$
\begin{gathered}
K(\omega)=\frac{\varepsilon_{p}^{*}-\varepsilon_{m}^{*}}{\varepsilon_{p}^{*}+\varepsilon_{m}^{*}}, \\
\varepsilon^{*}=\varepsilon-i \frac{\sigma}{\omega^{\prime}}
\end{gathered}
$$

where $i=\sqrt{ }-1$, and $\sigma$ is the electrical conductivity of a particle or medium. The DEP force is generally produced by an inhomogeneous electrode system such as castellated or interdigitated planar microelectrodes providing a non-uniform electric field [29,69,70,73-75]. The intensity of the applied electric field is highest in the region between two closely spaced electrodes. Particles experiencing 
electric field gradients are either attracted to or repelled from a high electric field region by the DEP force. The direction of the particle movement is determined by the frequency-dependent dielectric properties of a particle and the suspending medium [51] and is apparent from the sign of $\operatorname{Re}[K(\omega)]$ in Equation (2). If a particle is more polarizable than the surrounding medium, i.e., if $\operatorname{Re}[K(\omega)]>0$, the particle moves toward a strong electric field region experiencing positive DEP (p-DEP) (Figure 1a). Conductive particles in insulating fluids exhibit p-DEP behavior over all frequencies $[51,66]$. On the contrary, if a particle is less polarizable than the surrounding medium, i.e., if $\operatorname{Re}[K(\omega)]<0$, it migrates to a weak electric field region, repelled from a strong electric field region by negative DEP (n-DEP) (Figure 1b). Generally, polymer particles such as polystyrene or latex beads show n-DEP in a conductive electrolyte solution over megahertz frequencies $[51,67,76]$.

DEP has often been utilized for particle separation [66,68,77], transport [78], and sorting [79] in various fields because of several important advantages $[24,40,74]$. DEP can accumulate a large quantity of particles at a region close to or far from electrode edges immediately with application of a non-uniform electric field. Also, the object of manipulation is not limited to either a conductive or dielectric particle. DEP-based manipulation depends on the relative polarizability of a particle with respect to the surrounding medium, which relates to the electrical permittivity and conductivity of a particle and suspending medium [51]. DEP allows high flexibility in controlling particles suspended in fluid. In contrast, DEP sometimes needs a complicated 3D electrode structure to ensure the accuracy and precision of particle manipulation $[65,68,73,80-82]$. Although well-defined inhomogeneous electrodes are integrated in a microchannel, it is not easy to control nano-sized particles using DEP [51]. This is attributed to the proportionality of DEP force to the cube of particle radius $\left(r^{3}\right)$. Also, the technique operates more effectively in low conductivity solutions as a suspending medium for cell manipulation because Joule heating is proportional to electrical conductivity. However, most biological solutions have high electrical conductivity. The advantages and disadvantages of DEP have been covered in detail in recent reviews $[5,27]$.

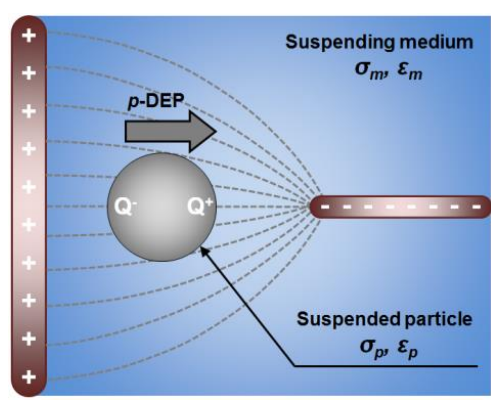

(a)

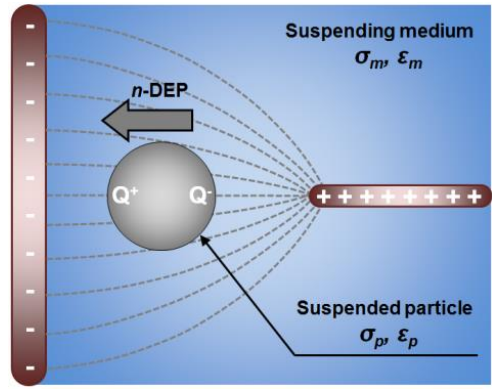

(b)

Figure 1. Dielectrophoretic (DEP) motion of a dielectric particle in a non-uniform electric field. (a) Positive dielectrophoresis, in which a dielectric particle moves toward a strong electric field region. (b) Negative dielectrophoresis, in which a dielectric particle migrates to a weak electric field region. Reproduced from [40], with the permission of AIP Publishing (2012).

\subsection{Electrophoresis}

Electrophoresis (EP) is defined as the motion of a charged particle relative to a stationary fluid, driven by an external electric field $[28,52,53,72]$. The direction and magnitude of the induced motion depend on the polarity and amount of net electrical charge of the particle, respectively [28,52]. Generally, electrophoretic force is produced by a pair of electrodes connected to a direct current (DC) power supply $[83,84]$. When electrodes are immersed in an ionic solution containing particles and an external DC electric field is provided to the electrodes, the particles experience electrophoretic force, moving toward the electrode possessing opposite polarity (Figure 2). The moving velocity of the 
particles, i.e., electrophoretic velocity $(v)$, is linearly proportional to the strength of the applied DC electric field $(E)[29,52]$.

$$
v=\mu_{e p} E
$$

where the electrophoretic mobility, $\mu_{e p}$, is the ability of a charged particle to move in response to an external electric field. It is expressed in two forms based on the relative magnitude of the Debye layer thickness $\left(\lambda_{D}\right)$ to the particle radius $\left(r_{p}\right)[28,29,72]$.

$$
\mu_{e p}=\left\{\begin{array}{l}
\frac{\varepsilon_{r} \varepsilon_{o} \zeta_{p}}{\eta_{f}}\left(\lambda_{D} \ll r_{p}\right) \\
\frac{2 \varepsilon_{r} \varepsilon_{o} \zeta_{p}}{3 \eta_{f}}\left(\lambda_{D} \gg r_{p}\right)
\end{array},\right.
$$

where $\varepsilon_{r}$ is the relative permittivity of the particle, $\varepsilon_{0}$ is the vacuum permittivity of free space, $\zeta_{p}$ is the zeta potential of the particle's surface, and $\eta_{f}$ is the viscosity of the surrounding fluid [85]. The variable $\zeta$ is defined as

$$
\zeta=\frac{\sigma \lambda_{D} r_{p}}{\varepsilon_{r} \varepsilon_{o}\left(\lambda_{D}+r_{p}\right)}
$$

When charged particles suspended in a fluid move by electrophoretic force, they are also subject to two other forces [40,86]: (1) fluid friction force and (2) electrophoretic retardation force. The friction force is the viscous drag force acting on electrophoretically moving particles. It depends on the size and shape of a particle and the viscosity of a surrounding fluid. The drag force increases for larger particles and higher fluid viscosities. The electrophoretic retardation force indicates the force exerted on movable ions in an EDL surrounding a charged particle. The ions have a polarity opposite to that of the particle and accordingly cause a fluid flow heading the opposite direction to the EP in an applied electric field. The flow results in a retardation effect on the electrophoretically induced motion.

EP has been mainly utilized for particle purification [87-90] and separation [83,91-96]. It has advantages of ease of particle manipulation and simplicity [24,27]. However, there are also several disadvantages [24]. First, EP is applicable only for charged particles; therefore, the range of relevant applications is not wide. Furthermore, the electrophoretic migration speed is relatively slow because the upper intensity of an applied DC electric field is restricted to avoid undesirable phenomena such as electrolysis.

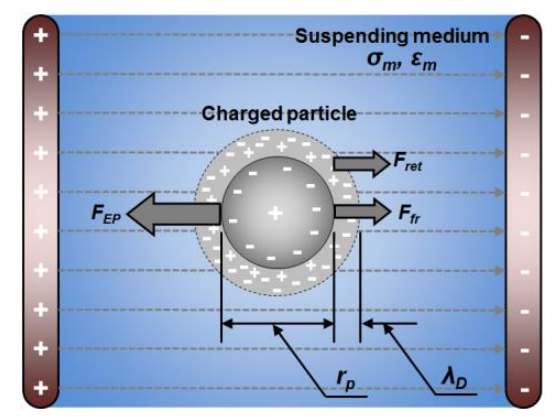

Figure 2. Electrophoretic motion of a charged particle in a direct current (DC) electric field. Reproduced from [40], with the permission of AIP Publishing (2012).

\subsection{Optical Tweezers}

Optical tweezers (OTs) are a method to control the motion of a single or few particles using a highly focused laser beam [32-34]. The focused beam induces particle motion, exerting three types of optical forces (Figure 3) [97]: (1) scattering force, (2) absorption force, and (3) gradient force. The optical scattering and absorption forces push a particle along the direction of propagation of a focused laser, balancing with the Stokes' drag in a fluid. For a spherical particle in the laser field with a Gaussian beam profile, the forces are expressed as $[34,97,98]$ 


$$
\begin{gathered}
F_{\text {scat }}=\frac{8 \pi I_{0} \alpha^{2} \varepsilon_{m}}{3 C_{0} \lambda^{4}}, \\
F_{a b s}=\frac{2 \pi \varepsilon_{m} I_{0}}{C_{0} \lambda} \operatorname{Im}[\alpha],
\end{gathered}
$$

where $I_{0}, C_{0}$, and $\lambda$ are the maximum intensity, speed, and wavelength of the incident laser light, respectively. The variable $\operatorname{Im}[$ ] represents the imaginary part of the brackets. The parameter $\alpha$ is given by

$$
\alpha=3 V_{p}\left(\varepsilon_{p}-\varepsilon_{m}\right) /\left(\varepsilon_{p}+2 \varepsilon_{m}\right)
$$

where $V_{p}$ is particle volume, and $\varepsilon_{p}$ and $\varepsilon_{m}$ are the electrical permittivities of the particle and suspending medium, respectively. The dielectric constants are a function of wavelength and consist of a real and an imaginary part, such that $\varepsilon=\varepsilon_{1}+i \varepsilon_{2}$, where $\varepsilon_{1}=n^{2}-k^{2}$ and $\varepsilon_{2}=2 n k$. Here, $n$ and $k$ are the refractive index and absorption coefficient, respectively. In addition to the scattering and absorption forces, the optical gradient force is defined as follows [34,97,98]:

$$
F_{\text {grad }}=\frac{2 \pi \nabla I_{0} \alpha}{C_{0}}
$$

where $\nabla I_{0}$ is the gradient of the incident laser intensity. It pulls a particle along the gradient or the reverse gradient of laser intensity, depending on the sign of the $\alpha$. For a non-absorbing dielectric particle, $\alpha$ is positive when the refractive index of the particle is larger than that of the surrounding medium. Then, the particle is attracted toward the region of highest laser intensity by the gradient force. On the contrary, when $\alpha$ is negative, the particle is repelled from the highest intensity region. For $\alpha>0$, the gradient force overwhelms the previously mentioned scattering and absorption forces in all directions. In this case, suspended particles in a fluid move along the gradient of laser intensity and stop moving at the laser beam waist, which is a stable trapping zone. This is the working principle of OTs.

In a general implementation of OTs, a near-infrared (NIR) laser beam is chosen as a driving laser source to minimize the optically-induced damage on target particles and reduce the level of fluctuation in laser power [99]. The laser beam is tightly focused by a high-numerical aperture (N.A.) objective lens to create the trapping zone $[32,34,100]$. Then, the beam waist behaves as a linear spring for particles in the vicinity of the laser focus. Near the beam waist, particles experience forces that are proportional to displacement from the center of the trapping zone.

OTs have been extensively used for transporting [34,97], sorting [6,34,54], and characterizing [27,54,101] particles with high-resolution. However, they cannot achieve high-throughput manipulation of particles because the beam waist of a focused laser used for trapping is very small [33,34]. Another problem is that excessive heating is produced during OT manipulation [33] and may cause thermal damage or change in the physical/chemical properties of the manipulated particles.

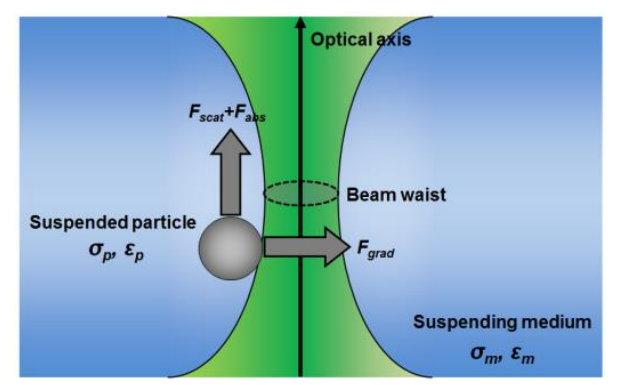

Figure 3. Trapping of a single particle by optical tweezers. Reproduced from [97], with the permission of The Royal Society of Chemistry (2011). 


\subsection{Magnetophoresis}

Magnetophoresis is the motion of a magnetic particle relative to a stationary fluid, driven by a non-uniform magnetic field (Figure 4) [35-38]. Magnetophoretically induced motion depends on the magnetic properties of the particle [38,40]: diamagnetism, paramagnetism, and ferromagnetism. Diamagnetism represents the property of magnetic materials that are magnetized in the opposite direction to an external magnetic field and are therefore repelled by an approaching magnet [102]. Most materials including water, mercury, copper, lead, gold, and silver are diamagnetic; superconductors have very high diamagnetism. The magnetic permeability of the materials is less than the permeability of free space $\left(\mu_{0}=4 \pi \times 10^{-7} \mathrm{Hm}^{-1}\right)$. Paramagnetism indicates the property of magnetic materials magnetized in a direction generally similar to an external magnetic field; accordingly, they are weakly attracted to an approaching magnet [103]. The magnetized status is not retained in the absence of the applied magnetic field because electron spins are randomized by thermal fluctuations. Representative paramagnetic materials include aluminum, oxygen, titanium, and iron oxide. Their relative magnetic permeability is slightly greater than 1 . Ferromagnetism refers to the property of materials strongly magnetized in the same direction as an external magnetic field $[38,103]$. The magnetization is retained for a long time after removal of the applied magnetic field. Thus, ferromagnetic materials behave like a permanent magnet. Iron, cobalt, and nickel are included in the category, and their magnetic permeability is very high compared to diamagnetic and paramagnetic materials.

When the three kinds of magnetic particles are subject to an external magnetic field, they experience a magnetic force $\left(F_{\text {mag }}\right)$ given by $[104,105]$

$$
F_{m a g}=\frac{\left(\chi_{p}-\chi_{m}\right) V_{p}}{\mu_{0}}(B \cdot \nabla) B
$$

where $V_{p}$ is the volume of a magnetic particle, $\mu_{0}$ is the permeability of free space, and $\chi_{p}$ and $\chi_{m}$ are the magnetic susceptibilities of a magnetic particle and suspending fluid, respectively. Magnetic susceptibility defines the degree of magnetization of a material by an applied magnetic field [38]. If the magnetic susceptibility of a particle is higher than that of a surrounding fluid, the particle migrates toward a higher magnetic field region. This phenomenon is termed positive magnetophoresis (Figure 4a) $[38,40]$. On the contrary, negative magnetophoresis occurs when the magnetic susceptibility of a particle is lower than that of the surrounding fluid (Figure $4 b$ ) $[38,40]$, causing to particle to a lower magnetic field. The definitions of positive and negative magnetophoretic motion of a particle are analogous to the DEP introduced earlier.

Magnetophoretic manipulation has been often utilized for colloidal separation, sorting, and transport [36-38,104-106]. In applications, magnetophoresis offers advantages for angular positioning and rotation of magnetic particles. Also, it can minimize the risk of particle damage during the manipulation process. However, magnetophoresis involves the magnetic hysteresis of micro-sized particles [55]. It causes the particles to agglomerate together into clusters even when the applied magnetic field is removed. 


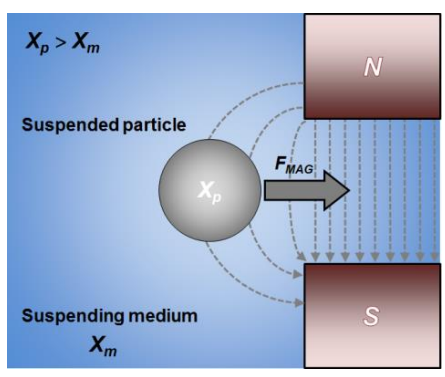

(a)

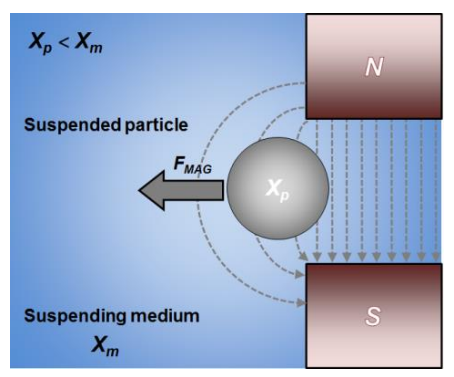

(b)

Figure 4. Magnetophoretic motion of a magnetic particle in a non-uniform magnetic field. (a) Positive magnetophoresis in which a magnetic particle migrates toward a higher magnetic field region. (b) Negative magnetophoresis in which a magnetic particle moves to a lower magnetic field region. Reproduced from [40], with the permission of AIP Publishing (2012).

\subsection{Acoustophoresis}

Acoustic waves with varying pressure profiles induce the movement of suspended particles relative to a stationary fluid, exerting an acoustic force on the particles. Such particle migration is defined as acoustophoresis (Figure 5) [39,41]. The acoustic force $\left(F_{a}\right)$ on particles is given by [41]

$$
\begin{gathered}
F_{a}=-\left(\frac{\pi P_{0}^{2} V_{p} \beta_{m}}{2 \lambda}\right) u(\beta, \rho) \sin \left(\frac{2 \pi x}{\lambda}\right), \\
u(\beta, \rho)=\frac{5 \rho_{p}-2 \rho_{m}}{2 \rho_{p}+\rho_{m}}-\frac{\beta_{p}}{\beta_{m}},
\end{gathered}
$$

where $V_{p}$ is the volume of a particle, $x$ is the distance to a nearest pressure node, $P_{0}$ and $\lambda$ are the pressure amplitude and wavelength of an acoustic wave, and $\beta$ and $\rho$ are liquid compressibility and density, respectively. The subscripts $p$ and $m$ indicate a particle and suspending medium, respectively. As seen in the equation, the acoustic force depends on various factors including the magnitude and frequency of the acoustic waves, the size and elasticity of the particle, and the surrounding fluid.

Particles in the influence of an acoustic wave are pushed to either the pressure nodes or the pressure anti-nodes (Figure 5a) $[39,40]$. The pressure nodes are the locations where pressure and density do not vary in the wave field. At the nodes, the acoustic wave forms a zero or minimum pressure. The pressure anti-nodes represent the locations where pressure and density show the largest variations. The acoustic wave produces the maximum pressure at the nodes. Suspended particles show acoustic wave-based motion depending on the pressure distribution. Then, the direction of particle motion can be explained based on the sign of the $u$ factor defined in Equaion (14) (Figure 5b). If $u$ is positive, the particles move toward the pressure nodes. On the contrary, if $u<0$, they show migration to the pressure anti-nodes.

Acoustophoresis provides the ability for size-, density-, and compressibility-based separation of particles $[39,49,107]$. Compressibility-based separation maximizes the strengths of acoustophoresis. Even though two particles have similar sizes and densities, if one particle is more compressible than a suspending fluid and the other particle is less compressible, their separation is achievable based on the compressibility difference. As such, a mixture of particles can be separated by an acoustic wave in a microchannel, and the separated particle groups can be collected at different outlets in a flowing fluid. A drawback of acoustophoretic manipulation is that it needs to integrate an acoustic wave resonator into a microfluidic structure for miniaturization and portability of the manipulation system $[27,107]$. In addition, controlling nano-sized particles using acoustophoresis is inefficient because the magnitude of the acoustic force acting on the particles is very small $[24,27]$. 


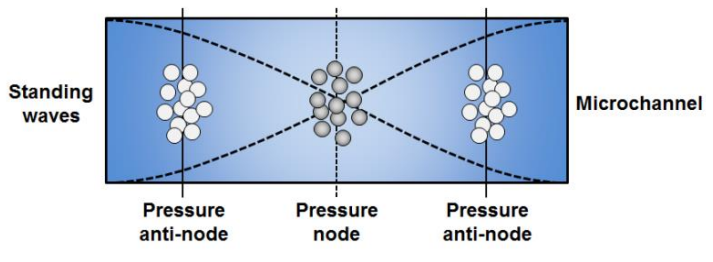

(a)

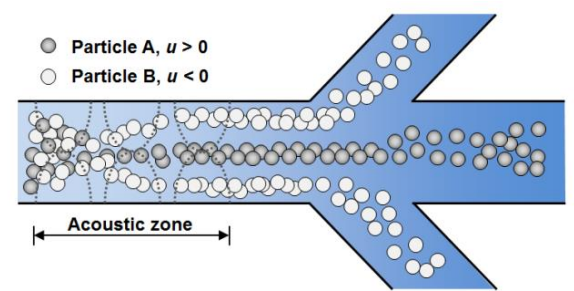

(b)

Figure 5. Acoustophoretic motion of suspended particles in an acoustic wave field. (a) Movement of particles by an acoustic standing wave with varying pressure profiles. (b) Density- and compressibility-based separation of particles by acoustophoresis. Reproduced from [108], with the permission of The Royal Society of Chemistry (2007).

\section{Rapid Electrokinetic Patterning}

Rapid electrokinetic patterning (REP) is a hybrid technique that utilizes simultaneous application of a uniform AC electric field and an optical laser beam for manipulation of a diverse set of particles $[26,58,60-63]$. While the two driving sources provide the electrokinetic effect and the optical effect, the combination of the two produces an additional electrothermal effect. Through coupling of the effects, REP can manipulate a large quantity of micro- and nano-sized particles at once at an arbitrary location in a microfluidic chip. The capability has been demonstrated by various experiments (Figure 6) [25,58,61-63,109]. In this section, we introduce the various aspects of REP, including the underlying principle, operating environment, and current challenges.

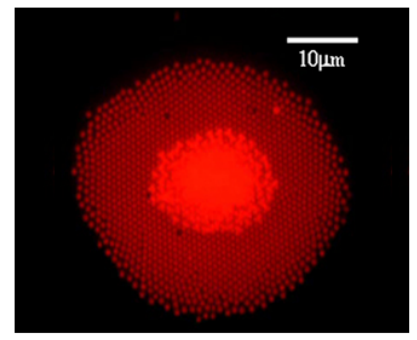

(a)

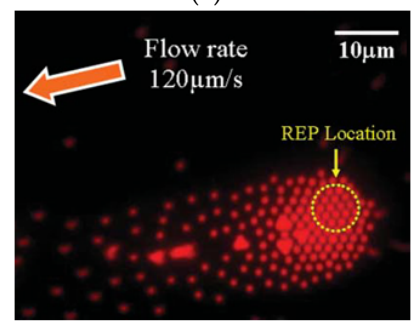

(d)

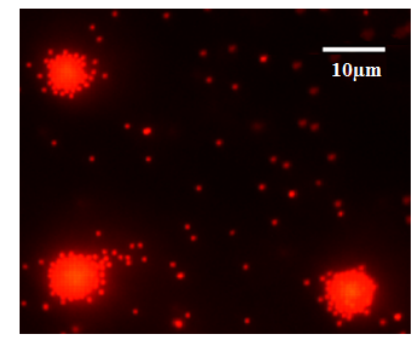

(b)

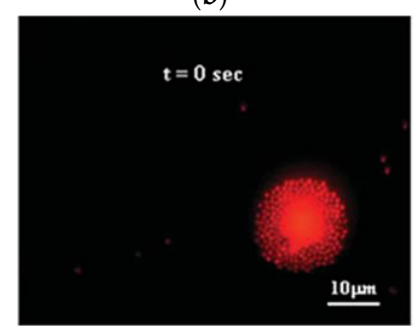

(e)

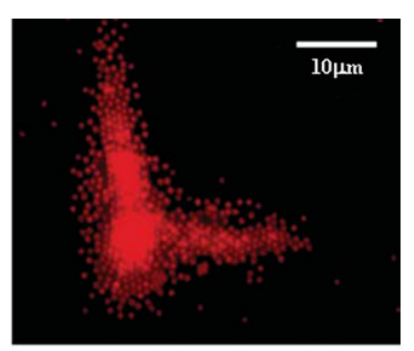

(c)

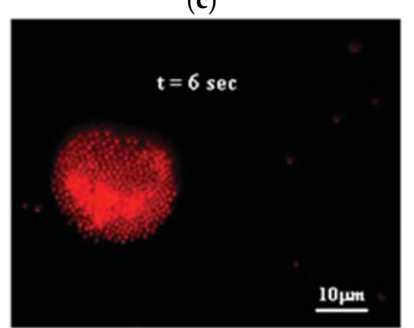

(f)

Figure 6. Manipulation of particles in a variety of forms by rapid electrokinetic patterning (REP). (a) REP-based aggregation; (b) REP-based patterning using multiple laser illuminations; (c) REP-based patterning by "L"-shaped illumination of a laser; (d) REP-based trapping in continuous flow of suspending medium; (e,f) REP-based translation. Reproduced from [63], with the permission of The Royal Society of Chemistry (2008). 


\subsection{Driving Environment of REP}

Generally, REP is realized in a simple microfluidic chip structure consisting of two parallel plate electrodes, a microchannel, and inlet and outlet reservoirs (Figure 7) [25,58,61-64]. In the REP chip, a transparent indium tin oxide (ITO)-coated glass substrate is used to create a pair of electrodes for particle flow visualization, imaging, and laser irradiation. However, since the coating material has a high electrical resistance, traditional conductors such as copper, gold, and chrome can replace the ITO. The two electrodes are separated by an insulating spacer $(\sim 100 \mu \mathrm{m})$ to create a microfluidic channel. Then, the top and bottom of the channel are directly exposed to the electrode surfaces. Suspensions of deionized water or low conductivity solutions $(\sigma<50 \mathrm{mS} / \mathrm{m})$ have previously been used in the REP chip [58,61-63]. High conductivity solutions $(\sigma>500 \mathrm{mS} / \mathrm{m})$ cause a strong Joule heating effect around the electrodes biased with an AC electric field; this leads to adhesion of suspended particles on the electrode surface, disturbing REP operation [72,110-113]. REP must also be adapted to manipulate particles suspended in high conductivity solutions for diverse applications in biotechnology.

AC frequencies below $200 \mathrm{kHz}$ are supplied to the electrodes to drive REP. AC frequencies above $200 \mathrm{kHz}$ decrease the effectiveness of REP operation, relaxing the interfacial polarization of manipulated particles. A focused laser is additionally provided in the presence of an applied electric field to either the top or bottom electrode surface. Since development of REP, an NIR laser $(\lambda \sim 1064 \mathrm{~nm})$ has often been utilized to produce local variations in temperature in a fluid. However, the laser is replaceable by other lasers that can induce the necessary temperature gradients at the proper combination of laser wavelength and electrode material. This feature is significant and useful because it allows REP to be replicated at different optical wavelengths.

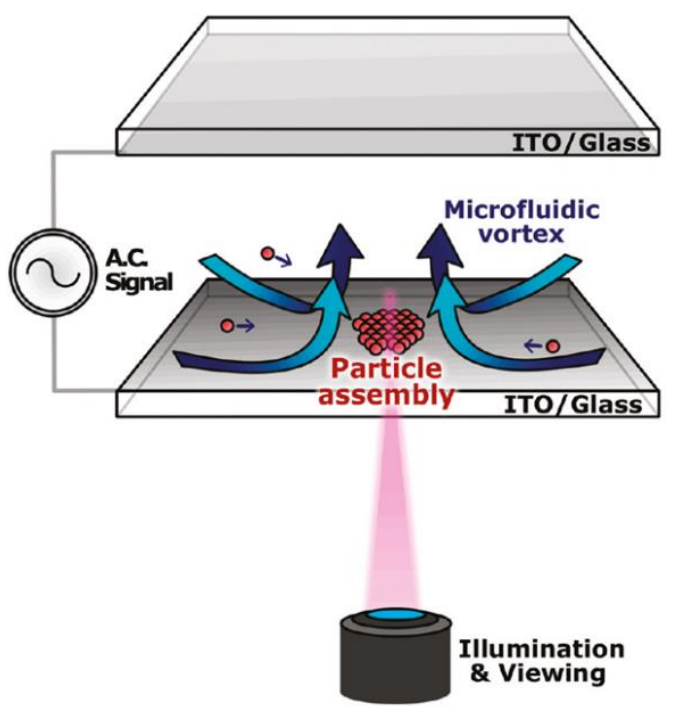

Figure 7. Microfluidic setup for REP realization consisting of two parallel-plate electrodes, a uniform alternating current (AC) electric field, and a focused laser beam. ITO: indium tin oxide. Reproduced from [58], with the permission of American Chemical Society (2010).

\subsection{Hybrid Feature of REP}

REP can be classified as a hybrid technique because it employs two different driving sources, i.e., a uniform AC electric field and a focused laser [24,61-63]. When the AC electric field is applied to a REP chip, colloidal particles suspended in a fluid are polarized in response to the field; at the same time, they are attracted to both of two electrode surfaces by long-range electrohydrodynamic (EHD) flow $[58,61,62]$. Then, the particles show an irregular distribution on the surfaces, forming small clusters. The focused laser beam creates thermal gradients in a fluid that interact with the applied electric field to produce a toroidal electrothermal (ET) vortex [114-116]. The ET vortex transports the particle clusters on the electrode surface toward the laser focal point. REP-based manipulation of 
particles becomes achievable when the two driving sources are simultaneously provided to induce the physical phenomena.

The hybrid nature of REP is shown in Figure 8. The simultaneous application of a uniform AC electric field and a focused laser to a REP chip initiates the aggregation of suspended particles on an electrode surface (Figure 8a). Turning the laser off makes the particles in the cluster scatter immediately on the electrode (Figure 8b). On the contrary, turning the AC electric field off causes the particles to be convected away from the electrode along the natural convection induced by laser heating (Figure 8c). These results demonstrate that REP cannot be realized by the application of one of the two driving sources.
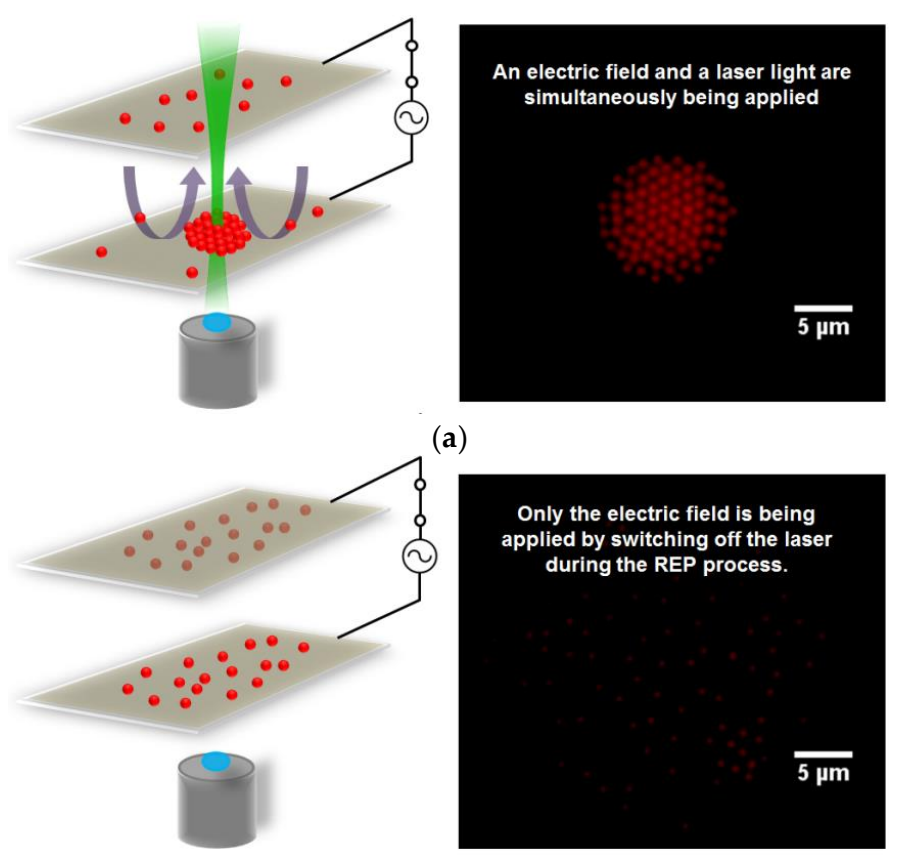

(b)

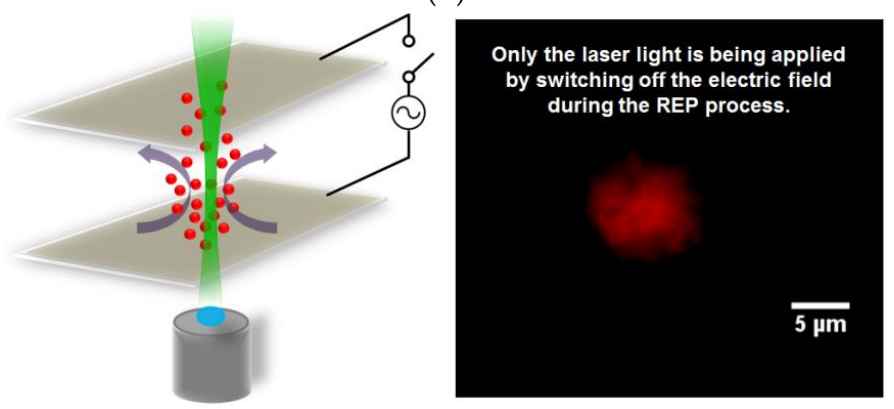

(c)

Figure 8. Hybrid features of REP. (a) Particle aggregation by the simultaneous application of a uniform AC electric field and a laser illumination. (b) Irregular distribution of particles on an electrode surface observed when turning off the applied laser only. (c) Convection of particles caused by turning off the applied electric field only. Reprinted/adapted by permission from (the RightsLink Permissions Springer Customer Service Centre GmbH): (Springer Nature) (Rapid Electrokinetic Patterning) by (Jae-Sung Kwon, Raviraj Thakur, Steven T. Wereley) (COPYRIGHT) (2012).

\subsection{Opto-Electrokinetic Physics of REP}

The REP-based manipulation of target particles is enabled by the three physical phenomena mentioned previously, i.e., interfacial polarization of particles, long-range EHD flow and ET fluid motion. The interfacial polarization of particles occurring by the interactions of the particle surface 
charges and ions in a fluid is typically characterized by the Maxwell-Wagner polarization frequency (M-W frequency) $[58,62,72]$. The $M-W$ frequency defines the behavior characteristic of ions in an electric double layer (EDL) surrounding a particle surface [72,117]. At AC frequencies below the $M-W$ frequency, cations and anions in the EDLs of particles are completely separated, forming dipoles. The dipoles give rise to constant electrostatic repulsion and attraction when the polarized particles are located on the electrode. The electrostatic repulsion and attraction are the forces acting between the particles themselves and between the particles and the electrode surface, respectively. At AC frequencies above the $\mathrm{M}-\mathrm{W}$ frequency, the ions do not have enough time to move and accumulate in response to the applied AC electric field. Accordingly, no dipoles form, and interfacial polarization does not happen. Recently, Kumar et al. used Voronoi diagrams and Delaunay triangulations to confirm that another polarization mechanism exists in the frequency region below the M-W frequency $[58,118]$. According to their experimental observation and topological analysis, the repulsive force between the polarized particles decreases with $\mathrm{AC}$ frequency even in the frequency band below the M-W frequency. This phenomenon is attributed to the non-equilibrium polarization of ions in the EDLs of the particles. It is closely associated with the critical frequency of REP, which will be introduced later [58]. EHD flow, a second mechanism, is one form of fluid flow that is induced by the mutual attraction which an applied electric field exerts on ions in a fluid. According to studies by Fagan et al. and Green et al., the flow affects the motion of particles on an electrode surface in an AC frequency region above $500 \mathrm{~Hz}$ [119-126]. It gathers the particles laterally, lifting them up slightly from the electrode surface. ET flow, a third mechanism, is driven by the coupling of the temperature-dependent gradients of electrical conductivity and permittivity with an applied electric field (Figure 9) [114-116]. The axisymmetric non-uniform temperature distribution in a fluid is produced by the highly focused laser beam, which is located on either a top or bottom electrode surface. The temperature gradient in turn induces spatial variations in the physical and electrical properties of the fluid such as density, permittivity and conductivity. The density gradient causes natural convection. Gradients in the electrical conductivity and permittivity produce an ET flow in an applied electric field. The natural convection is generally ignored in microfluidic systems where electric forces are present. Therefore, the ET flow is responsible for particle transport in REP process. The physical description of the flow is given by the time-averaged ET body force in Equation (15) [72,117].

$$
f_{e}=\frac{1}{2} \operatorname{Re}\left[\frac{\sigma \varepsilon(\alpha-\beta)}{\sigma+i \omega \varepsilon}(\nabla T \cdot E) E^{*}-\frac{1}{2} \varepsilon \alpha|E|^{2} \nabla T\right],
$$

where $\operatorname{Re}\left[\right.$ ] the real part of the bracket term, $E$ the applied electric field, $E^{*}$ its complex conjugate, $T$ the temperature, $\omega$ the applied angular frequency, and $\sigma$ and $\varepsilon$ present the electrical conductivity and permittivity of a fluid, respectively. The $\alpha$ and $\beta$ are defined as $(1 / \varepsilon)(\partial \varepsilon / \partial T)$ and $(1 / \sigma)$ $(\partial \sigma / \partial T)$, respectively.

The relationship between the three mechanisms for REP operation is illustrated in Figure 10a [24,64]. The application of a uniform AC electric field to a REP chip causes interfacial polarization of suspended particles and EHD motion of a fluid. The EHD flow transports the polarized particles toward an electrode surface. On the surface, the particles experience the competition and balance of several forces: (1) lateral repulsive forces between the particles ( $\left.F_{\text {particle-particle }}\right)$; $(2)$ vertical attractive forces between the particles and the electrode surface $\left(F_{\text {particle-electrode }}\right)$ and (3) local EHD-based hydrodynamic drag forces acting on the particle surfaces $\left(F_{\mathrm{EHD}}{ }^{\text {lateral }}\right.$ and $\left.F_{\mathrm{EHD}}{ }^{\text {vertical }}\right)$. The combined effect of the forces causes an irregular distribution of the particles and the localized formation of small particle clusters on the electrode surface. Then, the additional application of a focused laser produces an ET fluid flow. The flow exerts a drag force $\left(F_{\mathrm{ET}}\right)$ on the particles, carrying them toward the center of the laser beam. While the lateral component of the ET force $\left(F_{\mathrm{ET}}{ }^{\text {lateral }}\right)$ overwhelms the resulting force of $F_{\text {particle-particle }}$ and $F_{\mathrm{EHD}}$ lateral, the vertical component of the ET force $\left(F_{\mathrm{ET}}{ }^{\text {vertical }}\right)$ competes with $F_{\text {particle-electrode }}$ and $F_{\mathrm{EHD}}{ }^{\text {vertical }}$. When the three vertical forces balance each other at AC frequencies below $200 \mathrm{kHz}$, 
the particles transported by the ET flow form a large cluster on the electrode surface. This is the operating mechanism of the REP technique.

There is an interesting feature regarding the stability of REP manipulation. The number of particles in a REP-based cluster decreases gradually as the AC frequency increases above $200 \mathrm{kHz}$. At higher AC frequencies, the particles are no longer manipulated by REP and just are swept away in an ET microvortex. This instability of REP-based manipulation is due to an imbalance in the three vertical forces mentioned above, which is caused by a non-equilibrium polarization of the EDLs surrounding the particles. This implies that there is a critical point guaranteeing stable REP-based manipulation in applied AC frequencies. The point, referred to as a critical frequency $\left(f_{\mathrm{c}}\right)$, relates to the surface charge density $\left(\rho_{\mathrm{s}}\right)$ of suspended particles, i.e., $f_{\mathrm{c}} \sim \rho_{\mathrm{s}}$. This characteristic enables charge-based or size-based separation of colloidal particles by REP. For example, size-based separation of particles with a similar surface charge can be achieved by a critical frequency that is inversely proportional to particle surface area (Figure 10b). The details of REP physics, including the critical frequency, are found in the references $[58,61-63,114,115]$.
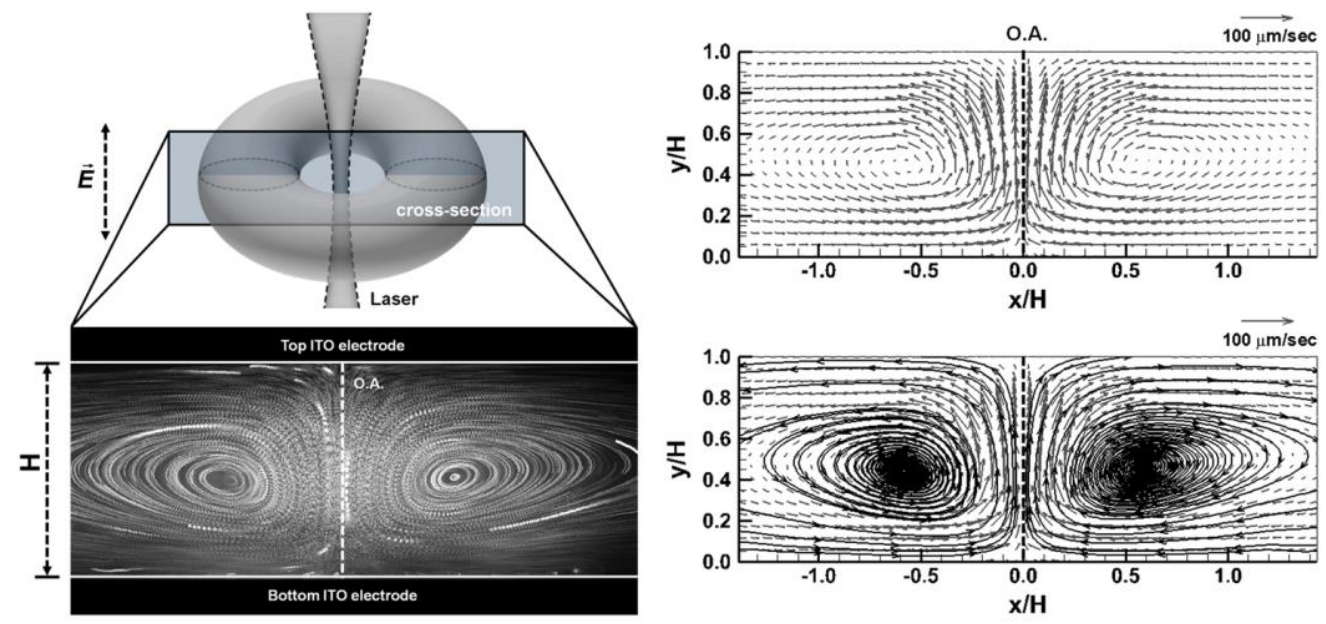

Figure 9. Visualization and particle image velocimetry (PIV) analysis of electrothermal microfluidic motion. Reprinted by permission from (the RightsLink Permissions Springer Customer Service Centre $\mathrm{GmbH})$ : (Springer Nature) (Microfluids and Nanofluids) [116], Copyright (2015).

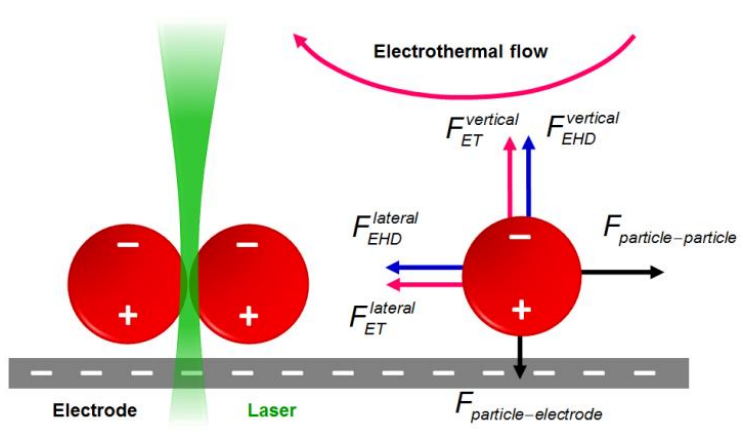

(a)

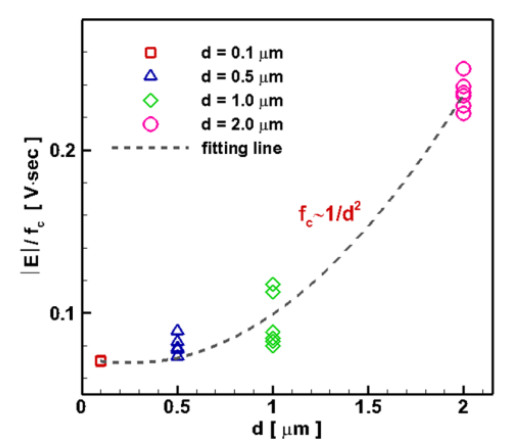

(b)

Figure 10. Physics of the REP technique. (a) Various forces involved in REP process. (b) Dependence of REP critical frequency on particle size. Reproduced from [58], with the permission of American Chemical Society (2010).

\subsection{Current Challenges of REP}

REP is a new form of particle manipulation technique that utilizes the simultaneous application of a uniform AC electric field and a focused laser. It has been steadily applied for concentration, 
trapping, patterning, and separation of micro- and nano-particles ranging from $22 \mathrm{~nm}$ to $10 \mu \mathrm{m}$, establishing its firm position in colloidal manipulation [25,58,61-63,109,127-129]. Recently, REP was also used for manipulation of swimming bacteria [130] and carbon nanotubes [131], extending its applicability in various fields including biotechnology. Despite its excellent capability, REP faces two challenges [25,58,61-63,109,127-131]: (1) the use of an expensive laser system as a heat source and (2) low manipulation efficiency of particles suspended in a high conductivity solution. These two problems should be overcome to find novel applications of REP for on-chip bioassays.

A $1064 \mathrm{~nm}$ wavelength NIR laser has been often used to create thermal gradients in a fluid in REP process. However, the high price and a large volume of the laser system affect the economics and portability of the REP technique. Therefore, finding an alternative heat source will enable various REP-based manipulations of particles at low cost. This issue is currently being resolved. Velasco et al. employed a micro-patterned thin film resistive heater instead of the optical laser [132]. The use of the heater during REP manipulation offered numerous benefits such as efficient supply of thermal energy to induce a non-uniform temperature field in a fluid. As previously mentioned, the other challenge is that it is very difficult to control particles suspended in a high conductivity electrolyte using REP $[24,25,64,130]$. A high conductivity solution produces strong Joule heating even in an external electric field with moderate intensity $[72,117,133]$. This causes the adhesion of particles on an electrode surface during REP manipulation. Because of that issue, REP has mostly been used to manipulate colloids suspended in low-conductivity solutions. However, it raises another problem in biotechnology that the low electrical conductivity of a suspending media hinders the viability of cells. To find wider biological applications, REP should also be adapted for manipulating particles in high conductivity electrolytes.

Author Contributions: J.-S.K. and J.H.O. contributed equally to this work as co-corresponding authors.

Acknowledgments: This work was supported by Basic Science Research Program through the National Research Foundation of Korea (NRF) funded by the Ministry of Education (No. 2016R1D1A1B03934976).

Conflicts of Interest: The authors declare no conflict of interest.

\section{References}

1. Whitesides, G.M. The origins and the future of microfluidics. Nature 2006, 442, 368-373. [CrossRef] [PubMed]

2. Gravesen, P.; Branebjerg, J.; Jensen, O.S. Microfluidics-A review. J. Micromech. Microeng. 1993, 3, $168-182$. [CrossRef]

3. Yi, C.; Li, C.-W.; Ji, S.; Yang, M. Microfluidics technology for manipulation and analysis of biological cells. Anal. Chim. Acta 2006, 560, 1-23. [CrossRef]

4. Castillo, J.; Dimaki, M.; Svendsen, W.E. Manipulation of biological samples using micro and nano techniques. Integr. Biol. 2009, 1, 30-42. [CrossRef] [PubMed]

5. Franke, T.A.; Wixforth, A. Microfluidics for miniaturized laboratories on a chip. ChemPhysChem 2008, 9 , 2140-2156. [CrossRef] [PubMed]

6. Jonáš, A.; Zemánek, P. Light at work: The use of optical forces for particle manipulation, sorting, and analysis. Electrophoresis 2009, 29, 4813-4851. [CrossRef] [PubMed]

7. Duineveld, P.C. The stability of ink-jet printed lines of liquid with zero receding contact angle on a homogeneous substrate. J. Fluid Mech. 2003, 477, 175-200. [CrossRef]

8. Soltman, D.; Smith, B.; Kang, H.; Morris, S.J.S.; Subramanian, V. Methodology for inkjet printing of partially wetting films. Langmuir 2010, 26, 15686-15693. [CrossRef] [PubMed]

9. Soltman, D.; Subramanian, V. Inkjet-printed line morphologies and temperature control of the coffee ring effect. Langmuir 2008, 24, 2224-2231. [CrossRef] [PubMed]

10. Wang, J.Z.; Zheng, Z.H.; Li, H.W.; Huck, W.T.S.; Sirringhaus, H. Dewetting of conducting polymer inkjet droplets on patterned surfaces. Nat. Mater. 2004, 3, 171-176. [CrossRef] [PubMed]

11. Jones, K.D.; Nakashima, M.; Bradshaw, C.J.; Papadopoulos, J.; Platzer, M.F. On flow separation control by means of flapping wings. In Bio-Mechanisms of Swimming and Flying; Kato, N., Ayers, J., Morikawa, H., Eds.; Springer: Tokyo, Japan, 2004. 
12. Barber, R.W.; Emerson, D.R. Optimal design of microfluidic networks using biologically inspired principles. Microfluid. Nanofluid. 2007, 4, 179-191. [CrossRef]

13. Chung, A.J.; Cordovez, B.; Jasuja, N.; Lee, D.J.; Huang, X.T.; Erickson, D. Implantable microfluidic and electronic systems for insect flight manipulation. Microfluid. Nanofluid. 2012, 13, 345-352. [CrossRef]

14. Nge, P.N.; Rogers, C.I.; Woolley, A.T. Advances in microfluidic materials, functions, integration, and applications. Chem. Rev. 2013, 113, 2550-2583. [CrossRef] [PubMed]

15. Tesař, V. Microfluidic valves for flow control at low reynolds numbers. J. Vis. 2001, 4, 51-60. [CrossRef]

16. Arai, F.; Kotani, K.; Maruyama, H.; Honda, A.; Ejima, M. On-chip robotics for biomedical innovation: Manipulation of single virus on a chip. In Proceedings of the 2009 9th IEEE Conference on Nanotechnology (IEEE-NANO), Genoa, Italy, 26-30 July 2009.

17. Liu, T.L.; Wen, X.; Kung, Y.-C.; Cru, P.-Y.C. Fabrication strategy for micro soft robotics with semiconductor devices integration. In Proceedings of the 2017 IEEE 30th International Conference on Micro Electro Mechanical Systems (MEMS), Las Vegas, NV, USA, 22-26 January 2017.

18. Belder, D. Microfluidics with droplets. Angew. Chem. Int. Ed. 2005, 44, 3521-3522. [CrossRef] [PubMed]

19. Kerkhoff, H.G. Testing microelectronic biofluidic systems. IEEE Des. Test Comput. 2007, 24, 72-82. [CrossRef]

20. McDonald, J.C.; Duffy, D.C.; Anderson, J.R.; Chiu, D.T.; Wu, H.; Schueller, O.J.A.; Whitesides, G.M. Fabrication of microfluidic systems in poly(dimethylsiloxane). Electrophoresis 2000, 21, 27-40. [CrossRef]

21. Bhagat, A.A.S.; Bow, H.; Hou, H.W.; Tan, S.J.; Han, J.; Lim, C.T. Microfluidics for cell separation. Med. Biol. Eng. Comput. 2010, 48, 999-1014. [CrossRef] [PubMed]

22. Wang, D.; Bodovitz, S. Single cell analysis: The new frontier in 'omics'. Trends Biotechnol. 2010, 28, $281-290$. [CrossRef] [PubMed]

23. He, J.-L.; Chen, A.-T.; Lee, J.-H.; Fan, S.-K. Digital microfluidics for manipulation and analysis of a single cell. Int. J. Mol. Sci. 2015, 16, 22319-22332. [CrossRef] [PubMed]

24. Kwon, J.-S.; Wereley, S.T. Towards new methodologies for manipulation of colloidal particles in a miniaturized fluidic device: Optoelectrokinetic manipulation technique. J. Fluids Eng. 2013, 135, 021306. [CrossRef]

25. Kwon, J.-S.; Ravindranath, S.P.; Kumar, A.; Irudayaraj, J.; Wereley, S.T. Opto-electrokinetic manipulation for high-performance on-chip bioassays. Lab Chip 2012, 12, 4955-4959. [CrossRef] [PubMed]

26. Kumar, A.; Williams, S.J.; Chuang, H.-S.; Green, N.G.; Wereley, S.T. Hybrid opto-electric manipulation in microfluidics-opportunities and challenges. Lab Chip 2011, 11, 2135-2148. [CrossRef] [PubMed]

27. Nilsson, J.; Evander, M.; Hammarström, B.; Laurell, T. Review of cell and particle trapping in microfluidic systems. Anal. Chim. Acta 2009, 649, 141-157. [CrossRef] [PubMed]

28. Melvin, M. Electrophoresis; John Wiley \& Sons: Chichester, UK, 1987.

29. Kwon, J.-S.; Maeng, J.-S.; Chun, M.-S.; Song, S. Improvement of microchannel geometry subject to electrokinesis and dielectrophoresis using numerical simulations. Microfluid. Nanofluid. 2008, 5, $23-31$. [CrossRef]

30. Kuzyk, A. Dielectrophoresis at the nanoscale. Electrophoresis 2011, 32, 2307-2313. [CrossRef] [PubMed]

31. Ashkin, A.; Dziedzic, J.M.; Yamane, T. Optical trapping and manipulation of single cells using infrared laser beams. Nature 1987, 330, 769-771. [CrossRef] [PubMed]

32. Curtis, J.E.; Koss, B.A.; Grier, D.G. Dynamic holographic optical tweezers. Opt. Commun. 2002, 2002, $169-175$. [CrossRef]

33. Kersaudy-Kerhoas, M.; Dhariwal, R.; Desmulliez, M.P.Y. Recent advances in microparticle continuous separation. IET Nanobiotechnol. 2008, 2, 1-13. [CrossRef] [PubMed]

34. Moffitt, J.R.; Chemla, Y.R.; Smith, S.B.; Bustamante, C. Recent advances in optical tweezers. Annu. Rev. Biochem. 2008, 77, 205-228. [CrossRef] [PubMed]

35. Kirby, B.J. Micro- and Nanoscale Fluid Mechanics: Transport in Microfluidic Devices; Cambridge University Press: New York, NY, USA, 2013; p. 536.

36. Pamme, N.; Eijkel, J.C.T.; Manz, A. On-chip free-flow magnetophoresis: Separation and detection of mixtures of magnetic particles in continuous flow. Jo. Magn. Magn. Mater. 2006, 307, 237-244. [CrossRef]

37. Pamme, N.; Manz, A. On-chip free-flow magnetophoresis: Continuous flow separation of magnetic particles and agglomerates. Anal. Chem. 2004, 76, 7250-7256. [CrossRef] [PubMed]

38. Suwa, M.; Watarai, H. Magnetoanalysis of micro/nanoparticles: A review. Anal. Chim. Acta 2011, 690, 137-147. [CrossRef] [PubMed] 
39. Friend, J. Microscale acoustofluidics: Microfluidics driven via acoustics and ultrasonics. Rev. Mod. Phys. 2011, 83, 647-704. [CrossRef]

40. Kayani, A.A.; Khoshmanesh, K.; Ward, S.A.; Mitchell, A.; Kalantar-zadeh, K. Optofluidics incorporating actively controlled micro- and nano-particles. Biomicrofluidics 2012, 6, 031501. [CrossRef] [PubMed]

41. Petersson, F.; Åberg, L.; Swärd-Nilsson, A.-M.; Laurell, T. Free flow acoustophoresis: Microfluidic-based mode of particle and cell separation. Anal. Chem. 2007, 79, 5117-5123. [CrossRef] [PubMed]

42. Gossett, D.R.; Tse, H.T.K.; Lee, S.A.; Ying, Y.; Lindgren, A.G.; Yang, O.O.; Rao, J.; Clark, A.T.; Carlo, D.D. Hydrodynamic stretching of single cells for large population mechanical phenotyping. Proc. Natl. Acad. Sci. USA 2012, 109, 7630-7635. [CrossRef] [PubMed]

43. Ekpenyong, A.E.; Whyte, G.; Chalut, K.; Pagliara, S.; Lautenschläger, F.; Fiddler, C.; Paschke, S.; Keyser, U.F.; Chilvers, E.R.; Guck, J. Viscoelastic properties of differentiating blood cells are fate- and function-dependent. PLoS ONE 2012, 7, e45237. [CrossRef] [PubMed]

44. Bamford, R.A.; Smith, A.; Metz, J.; Glover, G.; Titball, R.W.; Pagliara, S. Investigating the physiology of viable but non-culturable bacteria by microfluidics and time-lapse microscopy. BMC Biol. 2017, 15, 121. [CrossRef] [PubMed]

45. Pagliara, S.; Franze, K.; McClain, C.R.; Wylde, G.W.; Fisher, C.L.; Franklin, R.J.M.; Kabla, A.J.; Keyser, U.F.; Chalut, K.J. Auxetic nuclei in embryonic stem cells exiting pluripotency. Nat. Mater. 2014, 13, 638-644. [CrossRef] [PubMed]

46. Bhatt, K.H.; Grego, S.; Velev, O.D. An ac electrokinetic technique for collection and concentration of particles and cells on patterned electrodes. Langmuir 2005, 21, 6603-6612. [CrossRef] [PubMed]

47. Hwang, H. Rapid and selective concentration of microparticles in an optoelectrofluidic platform. Lab Chip 2009, 9, 199-206. [CrossRef] [PubMed]

48. Lapizco-Encinas, B.H.; Simmons, B.A.; Cummings, E.B.; Fintschenko, Y. Insulator-based dielectrophoresis for the selective concentration and separation of live bacteria in water. Electrophoresis 2004, 25, 1695-1704. [CrossRef] [PubMed]

49. Li, H.; Friend, J.R.; Yeo, L.Y. Surface acoustic wave concentration of particle and bioparticle suspensions. Biomed. Microdev. 2007, 9, 647-656. [CrossRef] [PubMed]

50. Jones, T.B. Electromechanics of Particles; Cambridge University Press: Cambridge, UK, 1995.

51. Pohl, H.A. Dielectrophoresis: The Behavior of Neutral Matter in Nonuniform Electric Fields; Cambridge University Press: New York, NY, USA, 1978.

52. Gaš, B. Theory of electrophoresis: Fate of one equation. Electrophoresis 2009, 30, S7-S15. [CrossRef] [PubMed]

53. Klepárník, K.; Boček, P. Electrophoresis today and tomorrow: Helping biologists' dreams come true. BioEssays 2010, 32, 218-226. [CrossRef] [PubMed]

54. Arai, F.; Ng, C.; Maruyama, H.; Ichikawa, A.; El-Shimy, H.; Fukuda, T. On chip single-cell separation and immobilization using optical tweezers and thermosensitive hydrogel. Lab Chip 2005, 5, 1399-1403. [CrossRef] [PubMed]

55. Lenshof, A.; Laurell, T. Continuous separation of cells and particles in microfluidic systems. Chem. Soc. Rev. 2010, 39, 1203-1217. [CrossRef] [PubMed]

56. Chiou, P.Y.; Ohta, A.T.; Wu, M.C. Massively parallel manipulation of single cells and microparticles using optical images. Nature 2005, 436, 370-372. [CrossRef] [PubMed]

57. Jamshidi, A.; Neale, S.L.; Yu, K.; Pauzauskie, P.J.; Schuck, P.J.; Valley, J.K.; Hsu, H.-Y.; Ohta, A.T.; Wu, M.C. Nanopen: Dynamic, low-power, and light-actuated patterning of nanoparticles. Nano Lett. 2009, 9, 2921-2925. [CrossRef] [PubMed]

58. Kumar, A.; Kwon, J.-S.; Williams, S.J.; Green, N.G.; Yip, N.K.; Wereley, S.T. Optically modulated electrokinetic manipulation and concentration of colloidal particles near an electrode surface. Langmuir 2010, 26, 5262-5272. [CrossRef] [PubMed]

59. Seo, H.-K.; Kim, Y.-H.; Kim, H.-O.; Kim, Y.-J. Hybrid cell sorters for on-chip cell separation by hydrodynamics and magnetophoresis. J. Micromech. Microeng. 2010, 20, 95019. [CrossRef]

60. Kumar, A.; Kwon, J.-S.; Williams, S.J. A novel optically driven electrokinetic technique for manipulating nanoparticles. Proc. SPIE 2009, 7400, 7400V.

61. Williams, S.J.; Kumar, A.; Green, N.G.; Wereley, S.T. A simple, optically induced electrokinetic method to concentrate and pattern nanoparticles. Nanoscale 2009, 1, 133-137. [CrossRef] [PubMed] 
62. Williams, S.J.; Kumar, A.; Green, N.G.; Wereley, S.T. Optically induced electrokinetic concentration and sorting of colloids. J. Micromech. Microeng. 2010, 20, 548-558. [CrossRef]

63. Williams, S.J.; Kumar, A.; Wereley, S.T. Electrokinetic patterning of colloidal particles with optical landscapes. Lab Chip 2008, 8, 1879-1882. [CrossRef] [PubMed]

64. Kwon, J.-S.; Thakur, R.; Wereley, S.T. Rapid electrokinetic patterning. In Encyclopedia of Nanotechnology; Bhushan, B., Ed.; Springer: Dordrecht, The Netherlands, 2012.

65. Cheng, I.-F.; Chang, H.-C. An integrated dielectrophoretic chip for continuous bioparticle filtering, focusing, sorting, trapping, and detecting. Biomicrofluidics 2007, 1, 21503. [CrossRef] [PubMed]

66. Gascoyne, P.R.C.; Vykoukal, J. Particle separation by dielectrophoresis. Electrophoresis 2002, 23, $1973-1983$. [CrossRef]

67. Green, N.G.; Morgan, H. Dielectrophoresis of submicrometer latex spheres. 1. Experimental results. J. Phys. Chem. B 1999, 103, 41-50. [CrossRef]

68. Hawkins, B.G.; Smith, A.E.; Syed, Y.A.; Kirby, B.J. Continuous-flow particle separation by 3d insulative dielectrophoresis using coherently shaped, dc-biased, ac electric fields. Anal. Chem. 2007, 79, 7291-7300. [CrossRef] [PubMed]

69. Kang, K.H.; Kang, Y.; Xuan, X.; Li, D. Continuous separation of microparticles by size with direct current-dielectrophoresis. Electrophoresis 2006, 27, 694-702. [CrossRef] [PubMed]

70. Park, S.; Koklu, M.; Beskok, A. Particle trapping in high-conductivity media with electrothermally enhanced negative dielectrophoresis. Anal. Chem. 2009, 81, 2303-2310. [CrossRef] [PubMed]

71. Morgan, H. Dielectrophoresis. In Encyclopedia of Microfluidics and Nanofluidics; Li, D., Ed.; Springer: New York, NY, USA, 2008; pp. 350-357.

72. Morgan, H.; Green, N.G. Ac Electrokinetics: Colloids and Nanoparticles; Research Studies Press LTD.: Baldock, UK, 2002; Volume 2, p. 326.

73. Cheng, I.-F.; Lin, C.-C.; Lin, D.-Y.; Chang, H.-C. A dielectrophoretic chip with a roughened metal surface for on-chip surface-enhanced raman scattering analysis of bacteria. Biomicrofluidics 2010, 4, 034104. [CrossRef] [PubMed]

74. Zhang, C.; Khoshmanesh, K.; Mitchell, A.; Kalantar-zadeh, K. Dielectrophoresis for manipulation of micro/nano particles in microfluidic systems. Anal. Bioanal. Chem. 2010, 396, 401-420. [CrossRef] [PubMed]

75. Washizu, M.; Jones, T.B. Multipolar dielectrophoretic force calculation. J. Electrost. 1994, 33, $187-198$. [CrossRef]

76. Arnold, W.M.; Schwan, H.P.; Zimmermann, U. Surface conductance and other properties of latex particles measured by electrorotation. J. Phys. Chem. B 1987, 91, 5093-5098. [CrossRef]

77. Morgan, H.; Hughes, M.P.; Green, N.G. Separation of submicron bioparticles by dielectrophoresis. Biophys. J. 1999, 77, 516-525. [CrossRef]

78. Choi, E.; Kim, B.; Park, J. High-throughput microparticle separation using gradient traveling wave dielectrophoresis. J. Micromech. Microeng. 2009, 19, 125014. [CrossRef]

79. Vahey, M.D.; Voldman, J. An equilibrium method for continuous-flow cell sorting using dielectrophoresis. Anal. Chem. 2008, 80, 3135-3143. [CrossRef] [PubMed]

80. Kung, Y.C.; Huang, K.W.; Chong, W.; Chiou, P.Y. Tunnel dielectrophoresis for tunable, single-stream cell focusing in physiological buffers in high-speed microfluidic flows. Small 2016, 12, 4343-4348. [CrossRef] [PubMed]

81. Kung, Y.-C.; Huang, K.-W.; Fan, Y.-J.; Chiou, P.-Y. Fabrication of 3d high aspect ratio pdms microfluidic networks with a hybrid stamp. Lab Chip 2015, 15, 1861-1868. [CrossRef] [PubMed]

82. Wang, L.; Flanagan, L.A.; Jeon, N.L.; Monuki, E.; Lee, A.P. Dielectrophoresis switching with vertical sidewall electrodes for microfluidic flow cytometry. Lab Chip 2007, 7, 1114-1120. [CrossRef] [PubMed]

83. Fonslow, B.R.; Bowser, M.T. Free-flow electrophoresis on an anodic bonded glass microchip. Anal. Chem. 2005, 77, 5706-5710. [CrossRef] [PubMed]

84. Hannig, K.; Wirth, H.; Meyer, B.-H.; Zeiller, K. Free-flow electrophoresis I. Theoretical and experimental investigations of the influence of mechanical and electrokinetic variables on the efficiency of the method. Biol. Chem. 1975, 356, 1209-1224. [CrossRef]

85. Hunter, R.J.; Ottewill, R.H.; Rowell, R.L. Zeta Potential in Colloid Science: Principles and Applications; Academic Press: London, UK, 1989; p. 398. 
86. Deyl, Z. Electrophoresis. A Survey of Techniques and Applications; Elsevier Science Ltd.: New York, NY, USA, 1982.

87. Schneyer, A.L.; Sluss, P.M.; Bosukonda, D.; Leo, E.; Reichert, J. Electrophoretic purification of radioiodinated follicle-stimulating hormone for radioligand receptor assay and radioimmunoassay. Endocrinology 1986, 119, 1446-1453. [CrossRef] [PubMed]

88. Hlaváček, A.; Sedlmeier, A.; Skládal, P.; Gorris, H.H. Electrophoretic characterization and purification of silica-coated photon-upconverting nanoparticles and their bioconjugates. Appl. Mater. Interfaces 2014, 6, 6930-6935. [CrossRef] [PubMed]

89. Radko, S.P.; Chrambach, A. Capillary zone electrophoresis of rigid submicron-sized particles in polyacrylamide solution selectivity, peak spreading and resolution. J. Chromatogr. A 1999, 848, 443-455. [CrossRef]

90. Li, F.; Hill, R.J. Nanoparticle gel electrophoresis: Bare charged spheres in polyelectrolyte hydrogels. J. Colloid Interface Sci. 2013, 394, 1-12. [CrossRef] [PubMed]

91. De Jesus, D.P.; Blanes, L.; de Lago, C.L. Microchip free-flow electrophoresis on glass substrate using laser-printing toner as structural material. Electrophoresis 2006, 27, 4935-4942. [CrossRef] [PubMed]

92. Kobayashi, H.; Shimamura, K.; Akaida, T.; Sakano, K.; Tajima, N.; Funazaki, J.; Suzuki, H.; Shinohara, E. Free-flow electrophoresis in a microfabricated chamber with a micromodule fraction separator: Continuous separation of proteins. J. Chromatogr. A 2003, 990, 169-178. [CrossRef]

93. Kohlheyer, D.; Besselink, G.A.J.; Schlautmann, S.; Schasfoort, R.B.M. Free-flow zone electrophoresis and isoelectric focusing using a microfabricated glass device with ion permeable membranes. Lab Chip 2006, 6, 374-380. [CrossRef] [PubMed]

94. Kremser, L.; Blaas, D.; Kenndler, E. Capillary electrophoresis of biological particles: Viruses, bacteria, and eukaryotic cells. Electrophoresis 2004, 25, 2282-2291. [CrossRef] [PubMed]

95. Roman, M.C.; Brown, P.R. Free-flow electrophoresis as a preparative separation technique. Anal. Chem. 1994, 66, 86A-94A. [CrossRef]

96. Turgeon, R.T.; Bowser, M.T. Micro free-flow electrophoresis: Theory and applications. Anal. Bioanal. Chem. 2009, 394, 187-198. [CrossRef] [PubMed]

97. Erickson, D.; Serey, X.; Chen, Y.-F.; Mandal, S. Nanomanipulation using near field photonics. Lab Chip 2011, 11, 995-1009. [CrossRef] [PubMed]

98. Svoboda, K.; Block, S.M. Optical trapping of metallic rayleigh particles. Opt. Lett. 1994, 9, 930-932. [CrossRef]

99. Morris, V.J. Atomic force microscopy (AFM) and related tools for the imaging of foods and beverages on the nanoscale. In Nanotechnology in the Food, Beverage and Nutraceutical Industries, 1st ed.; Huang, Q., Ed.; Woodhead Publishing: Cambridge, UK, 2014; pp. 99-148.

100. Smith, S.P.; Bhalotra, S.R.; Brody, A.L.; Brown, B.L.; Boyda, E.K.; Prentiss, M. Inexpensive optical tweezers for undergraduate laboratories. Am. J. Phys. 1999, 67, 26-35. [CrossRef]

101. Block, S.M.; Blair, D.F.; Berg, H.C. Compliance of bacterial flagella measured with optical tweezers. Nature 1989, 338, 514-518. [CrossRef] [PubMed]

102. Pshenichnikov, A.F.; Ivanov, A.S. Magnetophoresis of particles and aggregates in concentrated magnetic fluids. Phys. Rev. E 2012, 86, 051401. [CrossRef] [PubMed]

103. Watarai, H.; Suwa, M.; Iiguni, Y. Magnetophoresis and electromagnetophoresis of microparticles in liquids. Anal. Bioanal. Chem. 2004, 378, 1693-1699. [CrossRef] [PubMed]

104. Peyman, S.A.; Kwan, E.Y.; Margarson, O.; Iles, A.; Pamme, N. Diamagnetic repulsion-A versatile tool for label-free particle handling in microfluidic devices. J. Chromatogr. A 2009, 1216, 9055-9062. [CrossRef] [PubMed]

105. Rodríguez-Villarreal, A.I.; Tarn, M.D.; Madden, L.A.; Lutz, J.B.; Greenman, J.; Samitier, J.; Pamme, N. Flow focussing of particles and cells based on their intrinsic properties using a simple diamagnetic repulsion setup. Lab Chip 2011, 11, 1240-1248. [CrossRef] [PubMed]

106. Pamme, N. Magnetism and microfluidics. Lab Chip 2006, 6, 24-38. [CrossRef] [PubMed]

107. Evander, M.; Lenshof, A.; Laurell, T.; Nilsson, J. Acoustophoresis in wet-etched glass chips. Anal. Chem. 2008, 80, 5178-5185. [CrossRef] [PubMed]

108. Pamme, N. Continuous flow separations in microfluidic devices. Lab Chip 2007, 7, 1644-1659. [CrossRef] [PubMed] 
109. Velasco, V.; Work, J.A.H.; Williams, S.J. Electrokinetic concentration and patterning of colloids with a scanning laser. Electrophoresis 2012, 33, 1931-1937. [CrossRef] [PubMed]

110. Green, N.G.; Ramos, A.; González, A.; Castellanos, A.; Morgan, H. Electric field induced fluid flow on microelectrodes: The effect of illumination. J. Phys. D Appl. Phys. 2000, 33, L13-L17. [CrossRef]

111. Green, N.G.; Ramos, A.; González, A.; Castellanos, A.; Morgan, H. Electrothermally induced fluid flow on microelectrodes. J. Electrost. 2001, 53, 71-81. [CrossRef]

112. Green, N.G.; Ramos, A.; González, A.; Morgan, H.; Castellanos, A. Fluid flow induced by nonuniform ac electric fields in electrolytes on microelectrodes. I. Experimental measurements. Phys. Rev. E 2000, 61, 4011-4018. [CrossRef]

113. Green, N.G.; Ramos, A.; González, A.; Morgan, H.; Castellanos, A. Fluid flow induced by nonuniform ac electric fields in electrolytes on microelectrodes. III. Observation of streamlines and numerical simulation. Phys. Rev. E 2002, 66, 26305-26311. [CrossRef] [PubMed]

114. Kumar, A.; Cierpka, C.; Williams, S.J.; Kähler, C.J.; Wereley, S.T. 3d3c velocimetry measurements of an electrothermal microvortex using wavefront deformation ptv and a single camera. Microfluid. Nanofluid. 2011, 10, 355-365. [CrossRef]

115. Kumar, A.; Williams, S.J.; Wereley, S.T. Experiments on opto-electrically generated microfluidic vortices. Microfluid. Nanofluid. 2009, 6, 637-646. [CrossRef]

116. Kwon, J.S.; Wereley, S.T. Light-actuated electrothermal microfluidic motion: Experimental investigation and physical interpretation. Microfluid. Nanofluid. 2015, 19, 609-619. [CrossRef]

117. Ramos, A.; Morgan, H.; Green, N.G.; Castellanos, A. Ac electrokinetics: A review of forces in microelectrode structures. J. Phys. D Appl. Phys. 1998, 31, 2338-2353. [CrossRef]

118. Kumar, A.; Chuang, H.-S.; Wereley, S.T. Dynamic manipulation by light and electric fields: Micrometer particles to microliter droplets. Langmuir 2010, 26, 7656-7660. [CrossRef] [PubMed]

119. Fagan, J.A.; Sides, P.J.; Prieve, D.C. Vertical oscillatory motion of a single colloidal particle adjacent to an electrode in an ac electric field. Langmuir 2002, 18, 7810-7820. [CrossRef]

120. Fagan, J.A.; Sides, P.J.; Prieve, D.C. Vertical motion of a charged colloidal particle near an ac polarized electrode with a nonuniform potential distribution: Theory and experimental evidence. Langmuir 2004, 20, 4823-4834. [CrossRef] [PubMed]

121. Fagan, J.A.; Sides, P.J.; Prieve, D.C. Evidence of multiple electrohydrodynamic forces acting on colloical particle near an electrode due to an alternating current electric field. Langmuir 2005, 21, 1784-1794. [CrossRef] [PubMed]

122. Fagan, J.A.; Sides, P.J.; Prieve, D.C. Mechanism of rectified lateral motion of particles near electrodes in alternating electric fields below $1 \mathrm{khz}$. Langmuir 2006, 22, 9846-9852. [CrossRef] [PubMed]

123. Ristenpart, W.D.; Aksay, I.A.; Saville, D.A. Electrically guided assembly of planar superlattices in binary colloidal suspensions. Phys. Rev. Lett. 2003, 90, 128303. [CrossRef] [PubMed]

124. Ristenpart, W.D.; Aksay, I.A.; Saville, D.A. Assembly of colloidal aggregates by electrohydrodynamic flow: Kinetic experiments and scaling analysis. Phys. Rev. E 2004, 69, 214051-214058. [CrossRef] [PubMed]

125. Ristenpart, W.D.; Aksay, I.A.; Saville, D.A. Electrohydrodynamic flow around a colloidal particle near an electrode with an oscillating potential. J. Fluid Mech. 2007, 575, 83-109. [CrossRef]

126. Ristenpart, W.D.; Jiang, P.; Slowik, M.A.; Punckt, C.; Saville, D.A.; Aksay, I.A. Electrohydrodynamic flow and colloidal patterning near inhomogeneities on electrodes. Langmuir 2008, 24, 12172-12180. [CrossRef] [PubMed]

127. Work, A.H., Jr.; Williams, S.J. Characterization of $2 \mathrm{~d}$ colloid aggregations created by optically induced electrohydrodynamics. Electrophoresis 2015, 36, 1674-1680. [CrossRef]

128. Work, A.H., Jr.; Williams, S.J. Characterization of $2 \mathrm{~d}$ colloids assembled by optically-induced electrohydrodynamics. Soft Matter 2015, 11, 4266-4272. [CrossRef]

129. Wang, K.-C.; Kumar, A.; Williams, S.J.; Green, N.G.; Kim, K.C.; Chuang, H.-S. An optoelectrokinetic technique for programmable particle manipulation and bead-based biosignal enhancement. Lab Chip 2014, 14, 3958-3967. [CrossRef] [PubMed]

130. Mishra, A.; Maltais, T.R.; Walter, T.M.; Wei, A.; Williams, S.J.; Wereley, S.T. Trapping and viability of swimming bacteria in an optoelectric trap. Lab Chip 2016, 16, 1039-1046. [CrossRef] [PubMed]

131. Mishra, A.; Clayton, K.; Velasco, V.; Williams, S.J.; Wereley, S.T. Dynamic optoelectric trapping and deposition of multiwalled carbon nanotubes. Microsyst. Nanoeng. 2016, 2, 16005. [CrossRef] 
132. Velasco, V.; Williams, S.J. Electrokinetic concentration, patterning, and sorting of colloids with thin film heaters. J. Colloid Interface Sci. 2013, 394, 598-603. [CrossRef] [PubMed]

133. Zhou, H.; Götzinger, M.; Peukert, W. The influence of particle charge and roughness on particle-Substrate adhesion. Powder Technol. 2003, 135-136, 82-91. [CrossRef] 